\title{
Procurement and delivery of food at holiday provision clubs
}

\author{
Emily Mann a* \\ Northumbria University \\ Clara Widdison ${ }^{\mathrm{b}}$ \\ Mayor's Fund for London \\ Zeibeda Sattar ${ }^{\mathrm{c}}$ and Margaret Anne Defeyter ${ }^{\mathrm{d}}$ \\ Northumbria University
}

\begin{abstract}
Submitted December 14, 2020 / Revised May 13 and July 6, 2021 / Accepted July 6, 2021 /
Published online November 19, 2021

Citation: Mann, E., Widdison, C., Sattar, Z., \& Defeyter, M. A (2021). Procurement

and delivery of food at holiday provision clubs. Journal of Agriculture, Food Systems, and

Community Development, 11(1), 45-57. https://doi.org/10.5304/jafscd.2021.111.009
\end{abstract}

Copyright (C) 2021 by the Authors. Published by the Lyson Center for Civic Agriculture and Food Systems. Open access under CC-BY license.

\begin{abstract}
While school food initiatives across England support children's nutritional intake during school term time, there is no universal state provision during the school holidays to reduce the risk of children experiencing food insecurity. In the absence of a national program of holiday provision, community organizations in disadvantaged communities have established holiday clubs offering free food and activities to children. This paper exam-
\end{abstract}

a* Corresponding author: Emily Mann, Ph.D., Senior Research Assistant, Northumbria University, Newcastle upon Tyne, NE1 8ST, UK; emily.k.mann@,northumbria.ac.uk

b Clara Widdison, Mayor's Fund for London, City Hall, London, UK.

c Zeibeda Sattar, Ph.D., Lecturer, Northumbria University, Newcastle upon Tyne, NE1 8ST, UK.

d Margaret Anne Defeyter, Ph.D., Professor, Northumbria University, Newcastle upon Tyne, NE1 8ST, UK. ines how these holiday clubs source food and the challenges of procuring food and delivering healthy meals that adhere to UK School Food Standards. Results indicate that holiday clubs adopt a variety of procurement strategies including relying upon donated food. While club leaders have sought opportunities to source food cost-effectively, the

\section{Author Contributions}

All authors contributed to the study conception and design. Material preparation, data collection and analysis were performed by Emily Mann, Clara Widdison, Zeibeda Sattar and Margaret Anne Defeyter. The first draft of the manuscript was written by Emily Mann and all authors commented on previous versions of the manuscript. All authors read and approved the final manuscript.

\section{Funding Disclosure}

This study was funded by Mayor's Fund for London.

\section{Conflicts of Interest/Competing Interests}

The authors have no conflicts of interest to declare that are relevant to the content of this article. 
findings suggest significant challenges for these clubs to achieve their aim of delivering healthy meals. Findings point to needs for sustainable funding and the developing healthy food procurement policies and processes that align with a wider food strategy.

\section{Keywords}

Child, Food Insecurity, Food Procurement, School

Holidays, Holiday Provision, Community

Organizations

\section{Introduction and Literature Review}

A healthy diet in childhood is important for longterm health and development. Conversely, it is recognized that a high-energy diet together with physical inactivity can lead to obesity, type 2 diabetes, cardiovascular disease, some cancers, and osteoporosis (Joint World Health Organization

[WHO]/Food and Agriculture Organization of the United Nations [FAO] Expert Consultation on Diet, Nutrition and the Prevention of Chronic Diseases, 2003). Furthermore, frequent consumption of sugar dense food and drinks contributes to dental decay (Joint WHO/FAO Expert Consultation, 2003). The Eatwell Guide, developed by Public Health England, provides guidelines on the proportion of food types to achieve a healthy, balanced diet (Public Health England, 2016). A daily balanced diet should consist of at least five portions of fruit and vegetables, some starchy food, dairy, and protein-rich foods, while limiting the amounts of food high in saturated fat and salt, and food and drink high in added sugars (Public Health England, 2016; Scientific Advisory Committee on Nutrition [SACN], 2012). Despite these guidelines and the emphasis on obtaining a healthy diet, many factors influence food purchasing behavior: household income as well as resources, such as access to the internet, public transport, or a car (Burgoine et al., 2018; Dowler \& Lambie-Mumford, 2015; Ginn et al., 2016; Thornton et al., 2014). Moreover, one of the principal barriers for low socioeconomic groups to obtain a healthy diet is the cost of healthy food items, such as fruit and vegetables, and it is evident that these food items are more expensive than energy-dense food with poor nutritional value (Darmon \& Drewnowski, 2015; Jones et al., 2014; Williamson et al., 2017). The level of household income affects an individual's diet, and as deprivation increases, it is less likely that members of the household can afford not only healthy food but also housing with sufficient facilities to store and prepare meals (Board of Science, British Medical Association, 2015; Dimbleby, 2020; Marmot et al., 2010). Subsequently, households in the lowest income deciles do not have sufficient food budgets to meet the cost of achieving a healthy diet that accords to the Eatwell Guide (House of Lords, 2020; Scott et al., 2018), and these households are likely to experience food insecurity (Department for Health, 2005).

Food insecurity can be considered in the context of an individual's social and economic circumstances, with those less well off in society at risk of being food insecure (Long et al., 2020). This has a direct effect on their social determinants of health; a social gradient exists, with the poorest in society experiencing worse health outcomes than their wealthier peers (Marmot et al., 2010, 2020). Recent evidence submitted to the House of Lord's Select Committee on Food, Poverty, Health and Environment indicate that local food environments have a negative impact on lower-income groups and contribute to rising health inequalities as outlets selling less healthy food, including fast food outlets, are more likely to be concentrated in disadvantaged neighborhoods (House of Lords, 2020; Public Health England, 2018). Thus, it is unsurprising that adults and children living in deprived areas are significantly more likely to become obese or suffer from diet-related ill health (House of Lords, 2020; Marmot et al., 2020).

The Household Below Average Income (HBAI) figures published by the Department for Work and Pensions (DWP) in March 2020 indicate that 14.5 million people were living in relative poverty in the UK in 2018/19 (DWP, 2021). Of this total, 4.2 million were children, equivalent to around a quarter of all children or eight in a classroom of 30 children, and this figure has increased by over 500,000 since 2010 (DWP, 2021). Until recently, household food security has not been routinely measured in the UK. The Food Standards Agency's results from Wave 5 (2018 data) of the Food and You survey revealed that $10 \%$ of adults 
lived in households with low or very-low food security, and approximately one in six adults (17\%) reported that their household worried in the last 12 months about running out of food before there was money to buy more (Food Standards Agency, 2019).

The Department for Education (DfE) and the Department of Health subsidize several policies during school term time to support the nutritional needs of children from low-income families. These initiatives include Free School Meals (FSM) for families receiving income support, Universal Infant FSM for all children aged 4 to 7 years, breakfast club provision, and the School Fruit and Vegetable Scheme for children aged 4 to 6 years. Furthermore, all food served to pupils in schools must comply with School Food Standards and be nutritious and of a high quality (DfE, 2016). Recent research on school-based food intervention programs demonstrate that they can play an important role in improving healthy eating behaviors or decreasing the body mass index (BMI) of children (Driessen et al., 2014; Van Cauwenberghe et al., 2010; Wang \& Stewart, 2013). Niebylski et al. (2014) conducted a review of healthy food procurement policies in the U.S., Canada, and the UK, and findings from this review established that healthy food procurement policies can increase healthy eating behaviors across a range of settings, such as schools, hospitals, government institutions, and remote communities. Healthy food procurement policies increased the availability of healthier food and decreased purchases of food high in fat, sodium, and sugar, along with improved attitudes toward healthy eating (Niebylski et al., 2014). Furthermore, the implementation of healthy food procurement programs in schools has demonstrated enhanced food security and health benefits for children (Niebylski et al., 2014; Swensson \& Tartanac, 2020).

Despite these school-based policies to encourage the intake of healthy food items, there is no universal state provision to support the nutritional needs of children during the school holidays. In the UK, schools are required to open for 190 days per year (R. Long, 2019). Thus, there are approximately 14 weeks of the year when schools are closed. It is evident that families can experience increased financial pressure and risk experiencing holiday food insecurity when FSM provision is not available and parents resort to skipping meals or buying poor quality or unhealthy food to ensure their children are fed (Defeyter et al., 2015; Dowler \& Lambie-Mumford, 2015; Gill \& Sharma, 2004; M. A. Long et al., 2018; Ridge, 2002). Moreover, it is evident that some families are forced to seek emergency food provision, i.e., foodbanks, during the school holidays. While foodbank usage is considered a poor indicator and underestimates the prevalence of food insecurity (Loopstra \& Tarasuk, 2015), in 2018 the national network of foodbanks, the Trussell Trust, provided 87,496 emergency three-day food parcels to children in the UK during the school summer holidays (Trussell Trust, 2019).

In response to concerns about children experiencing holiday food insecurity, community groups, local authorities, schools and faith groups have established holiday clubs in economically deprived neighborhoods to provide free food and activities to children during the school holidays. Recent research on holiday provision has demonstrated a need to support families as a result of the increased financial hardship and risk of isolation during the school holidays (Graham et al., 2016, Mann et al., 2020) and identified a range of social, wellbeing, and health benefits for attendees (Defeyter et al., 2015; Graham et al., 2016; Holley et al., 2019; Morgan et al., 2019). More recently, governments across the devolved nations of the UK have pledged funding to support programs of holiday provision, albeit these funding initiatives vary in scale and are not evenly distributed among disadvantaged communities (Mann et al., 2018). For example, the DfE provided funding of $f 9 \mathrm{~m}$ in 2020 for a Holiday Activity and Food Program to support holiday provision during the six-week school summer holidays for 50,000 children across 17 areas of England. However, this falls short of the 1.3 million children eligible for FSM provision (DfE, 2019). In 2019, the Department for Environment, Food and Rural Affairs (Defra) commissioned an independent review into the UK food system to develop a national food strategy, and recommendations for establishing a food system that supports disadvantaged children were published in 
August 2020. A recommendation from part one of this strategy promotes the extension of the government-funded Holiday Activity and Food Program to ensure that all children in receipt of FSM provision have access to holiday provision (Dimbleby, 2020).

In the absence of statutory funding for holiday provision, community organizations rely upon a range of networks to help deliver this provision (Mann et al., 2020; Stretesky et al., 2020). Conversely, schools use the purchasing power of local authorities or multi-academy trusts to negotiate contracts and purchase food through catering organizations. While some community organizations use catering organizations to source food and meals, many community organizations lack the purchasing power or storage facilities to benefit from bulk purchases. Thus, to purchase food and deliver holiday provision that is free to the user, community organizations have developed a range of food procurement strategies and rely on a range of networks and connections in their communities (Stretesky et al., 2020). Community organizations delivering holiday provision try to serve healthy food; however, in the absence of statutory guidelines there is variation across settings of what constitutes a healthy meal (Holley et al., 2019). A condition of community organizations to participate in the DfE-funded Holiday Activity and Food program as well as some regional holiday provision schemes is to provide food that complies with School Food Standards. Nevertheless, there is currently no statutory obligation for providers of holiday provision to adhere to national food standards, and how food is sourced and prepared at holiday clubs is a public health concern. The aims of this paper are to fill the gap in the literature and investigate how holiday clubs source food for their holiday provision and the challenges of procuring food and delivering meals to children living in disadvantaged neighborhoods, and inform future delivery of holiday provision programs.

\section{Applied Research Methods}

\section{Kitchen Social}

The current study reports findings from data col- lected during an evaluation of holiday provision in London operated by the Mayor's Fund for London's program of holiday provision, "Kitchen Social." Kitchen Social was launched in 2017 in response to child poverty rates in London and the challenges faced by low-income families in accessing affordable, healthy food during the school holidays (Mayor's Fund for London, 2019). London has the highest rates of poverty compared to other English regions, and in 2017/18, 37\% of London's children (approximately 700,000) were living in poverty (Leeser, 2020). Community organizations participating in the Kitchen Social program of holiday provision are referred to as holiday hubs. During the summer of 2019, Kitchen Social supported 53 community organizations to deliver holiday provision across London from 78 holiday hubs. Holiday hubs receive funding from Kitchen Social to contribute toward the cost of food and activities at their hub. The hubs are located in disadvantaged neighborhoods and offer a universal, free holiday program to children living locally. Over two-thirds of Kitchen Social hubs $(N=59)$ are located in the top $20 \%$ of the most deprived neighborhoods in England according to the 2019 Income Deprivation Affecting Children Index (IDACI), a subset of the English Indices of Deprivation 2019 that measures the proportion of all children under the age of 16 living in income deprived families (Ministry of Housing Communities \& Local Government, 2019). The holiday hubs operate from a range of settings, including community centers, schools, youth clubs and adventure playgrounds. The research team conducted an evaluation of Kitchen Social during 2018 and 2019 that included both qualitative and quantitative methods to understand the implementation, reach, dose, and fidelity of Kitchen Social's holiday provision program. The aim of this paper is to investigate one particular aspect of the evaluation: the procurement of food and delivery of meals at holiday hubs. This study is a mixed-methods design and includes analysis of management data, a survey of holiday club staff, and structured observational data.

Full ethical approval for this study was obtained from Northumbria University's Faculty of Health and Life Sciences Ethics Committee. 


\section{Participants}

All staff leaders of holiday hubs participating in the Kitchen Social holiday program during the summer of 2019 ( $N=53)$ were invited to participate in this study, and 42 hub leaders took part.

\section{Instruments and Procedure}

\section{Online survey}

A survey, hosted by Online Surveys (formerly BOS), was distributed online and a weblink to the survey was emailed to all hub leaders. The survey consisted of a series of closed and open-ended questions designed to gather data about the Kitchen Social hubs and delivery of holiday provision. Questions focused on the challenges with sourcing food, challenges with preparing meals, the skills of staff and volunteers, and funding. The survey was active from 12 August until 24 September 2019.

\section{Management data}

The research team and Kitchen Social designed a data collection booklet to enable hub leaders to record data on child holiday hub attendees and the number of meals served on a daily basis. A paper copy of the data collection booklet was distributed to all hub leaders, who were asked to complete the booklet on each day the hub was open during summer 2019. Hub leaders were asked to return the completed booklet to the research team via Kitchen Social by post or email. One hub did not send data to the research team, so this hub was excluded from further analysis.

\section{Observational schedule}

A nonparticipant observational schedule was developed for the researcher to record the locations and timings of food preparation, and the delivery and serving models used in a sample of holiday hub settings. The purpose of the observation schedule was to provide further information on how food is sourced and prepared at holiday hubs and the facilities and equipment available to staff to prepare the meals. All holiday hubs were invited to participate in this observational phase of the study, and four case study sites were selected to represent the range of sites from which hubs were operating: two at community centers, one at a youth club, and one at an adventure playground. A research information sheet and consent form were sent and completed by each of the four holiday hub leaders prior to hub visits.

\section{Data Analysis}

Descriptive statistics of survey data and management records were calculated to describe the sample and examine the procurement of food and delivery of meals at holiday hubs. Thematic analysis was used to analyze the data from the open-ended questions in the survey. The research team reviewed the responses, after which the following method was adopted: line-by-line open coding (descriptive labelling), axial coding (clustering relationships, links and associations), and selective coding (exploring key codes and variables). Data from the nonparticipant structured observations were used to explain and understand findings from the management records and hub leaders' survey and the challenges of food procurement, food storage, and meal preparation.

By adopting quantitative and qualitative methods, this study aims to provide rich, meaningful insights into the procurement of food and delivery of meals at holiday hubs.

\section{Results}

\section{Descriptive Information on the Holiday Hubs}

A total of 42 hub leaders completed the online survey and represented community organizations that operate either a single-site hub $(n=30)$ or multiple hubs $(n=12)$. Descriptive data about the frequency, attendance, and meals served at the holiday hubs are presented in Table 1. On average, holiday hubs offered 14.3 days of holiday provision, approximately half the number of days of the school summer holiday. An average of 29 children attended each of the holiday hubs' sessions, with an equal split of males and females. Holiday hubs attracted a greater proportion of preschool and primary-school aged children compared to young people aged 12 years and over. In total, the holiday hubs in the current study served over 21,000 meals, and at least one meal was provided to every attendee at each session. 


\begin{tabular}{|c|c|c|c|c|c|}
\hline \multirow{4}{*}{$\begin{array}{l}\text { Descriptive data } \\
\text { about the types of } \\
\text { meals served at } \\
\text { Kitchen Social hubs } \\
\text { are presented in }\end{array}$} & \multicolumn{5}{|c|}{$\begin{array}{l}\text { Table 1. Descriptive Statistics on Holiday Hubs (Delivery of Provision) and } \\
\text { Number of Meals Served During the School Summer Holidays }\end{array}$} \\
\hline & & & & & $(N=42)$ \\
\hline & \multicolumn{4}{|c|}{ Mean number of days hub open during summer 2019 (SD) } & $14.3(7.1)$ \\
\hline & \multicolumn{5}{|c|}{ Attendance: } \\
\hline Table 2. The major- & \multicolumn{4}{|c|}{ Mean number of children attending a hub per day (SD) } & $29.0(17.2)$ \\
\hline ity of hubs served & \multicolumn{5}{|c|}{ Gender: } \\
\hline lunch and over a & \multicolumn{4}{|c|}{ Mean number of males attending a hub per day (SD) } & $14.6(9.0)$ \\
\hline third of hubs served & \multicolumn{4}{|c|}{ Mean number of females attending a hub per day (SD) } & $14.1(8.8)$ \\
\hline or more meals & \multicolumn{5}{|c|}{ Age: } \\
\hline at each session. & \multicolumn{4}{|c|}{ Mean number of children aged $<8$ years attending a hub per day (SD) } & $11.6(8.9)$ \\
\hline Moreover, over & \multicolumn{4}{|c|}{ Mean number of children aged 8-11 years attending a hub per day (SD) } & $13.5(8.4)$ \\
\hline & \multicolumn{4}{|c|}{ Mean number of young people aged $12-16$ years attending a hub per day (SD) } & $8.2(8.7)$ \\
\hline & \multicolumn{4}{|c|}{ Mean number of young people aged over 16 years attending a hub per day (SD) } & $6.7(6.3)$ \\
\hline served a hot meal at & \multicolumn{5}{|c|}{ Meals: } \\
\hline & \multicolumn{4}{|c|}{ Total number of meals served } & 21,156 \\
\hline & \multicolumn{4}{|c|}{ Mean number of meals served at hub per day (SD) } & $32.8(19.2)$ \\
\hline \multicolumn{6}{|l|}{$\begin{array}{l}\text { Food Procurement } \\
\text { Strategies }\end{array}$} \\
\hline \multicolumn{2}{|c|}{$\begin{array}{l}\text { To cover the cost of food, holiday hub leaders } \\
\text { used multiple food procurement strategies, } \\
\text { including receiving weekly food donations }\end{array}$} & \multicolumn{4}{|c|}{$\begin{array}{l}\text { Table 2. Descriptive Information on the Number and } \\
\text { Percentage of Kitchen Social Holiday Hubs Serving Meals } \\
\text { ( } N=41 \text { due to missing data) }\end{array}$} \\
\hline \multirow{2}{*}{\multicolumn{2}{|c|}{$\begin{array}{l}\text { from surplus food redistribution organizations } \\
\text { and food aid charities; sourcing food locally }\end{array}$}} & Meals served at hub & Number of hubs & Perce & ntage of hubs \\
\hline & & Breakfast & 10 & & 23.8 \\
\hline \multicolumn{2}{|c|}{ from food stores and wholesalers; receiving } & Lunch & 39 & & 92.9 \\
\hline \multirow{2}{*}{\multicolumn{2}{|c|}{$\begin{array}{l}\text { meals prepared by local restaurants, local } \\
\text { community organizations, or in-house catering }\end{array}$}} & Tea / Dinner & 7 & & 16.7 \\
\hline & & Snacks & 6 & & 14.3 \\
\hline \multirow{3}{*}{\multicolumn{2}{|c|}{$\begin{array}{l}\text { teams; receiving produce from community } \\
\text { food-growing projects; and/or relying on } \\
\text { additional funding from other organizations. }\end{array}$}} & 1 meal per session & 27 & & 65.9 \\
\hline & & 2 meals per session & 13 & & 31.7 \\
\hline & & 3 meals per session & 1 & & 2.4 \\
\hline
\end{tabular}

While the findings suggest a number of advantages of adopting these procurement strategies, hub leaders shared several challenges regarding the sourcing and provision of food that complies to the School Food Standards.

Holiday hub leaders reported the advantages of employing multiple food procurement methods: cost effective means of sourcing food; enough food sourced to ensure all children received at least one meal at a holiday hub session; brokered positive relationships with local food stores, restaurants, and community organizations; and holiday hub staff acquired skills and experience in preparing meals with food sourced from surplus food.

Hub leaders employed a variety of methods for sourcing food; in particular, they relied on regular free donations from surplus food redistribution organizations and food aid charities, which helped

the holiday hubs to reduce their spending on food items. As noted by one interviewee, "We use the food from The Felix Project and then buy other ingredients depending on what we cook" (Hub leader 13). Attendance at holiday hubs varied on a daily basis that made planning and budgeting for food difficult. Thus, hub leaders relied upon food donations in addition to purchasing food items to ensure that they were able to feed all children and young people, particularly on days when attendance was high. An interviewee said, "With surplus food from the Felix Project and FareShare and budget from Kitchen Social, we were able to provide enough food for all attending" (Hub leader 28).

Respondents reported that they brokered relationships with local food stores, wholesalers, restaurants, catering colleges, and community 
organizations to help source food and meals. By developing relationships with local food stores and wholesalers, hub leaders were able to secure discounts on their food orders: "We source our food from local shops and Halal meat from West Kensington. We get a little discount as they know the food is for the children and young people" (Hub leader 43). Six of the hub leaders reported that they outsourced the food procurement and meal preparation to a food aid charity, community organization, local restaurant, catering company, or catering college. Findings from observational records illustrated that one community center had developed a partnership with a local catering college to offer an internship for a student chef to prepare and serve all the meals at the hub. The student chef received regular visits from his tutor and gained practical experience in mass catering.

Finally hub leaders who had previously delivered holiday provision utilized their prior experience to create meal planners that children would eat and enjoy, and that could easily be adapted depending on surplus food donations. According to one interviewee, "We had challenges last year, with finding good volunteers, creating a menu that the children would eat, and the amount of time spent in the kitchen by staff to supervise the volunteers. We learnt from that and this year was much smoother. The volunteers that returned this year were now used to planning menus, and the children were more open to trying different food" (Hub leader 18). Moreover, it is evident from the observational findings that children were actively encouraged to participate in food preparation at the hubs by chopping and preparing vegetables, planning and serving meals, and offering training to young people to obtain a food hygiene certificate.

While the findings demonstrated the advantages of sourcing food from a variety of means to ensure all attendees received a meal during the holiday hub sessions, $21.4 \%(n=9)$ of hub leaders reported challenges in sourcing food, and 31\% $(n=13)$ experienced challenges with preparing meals. The main themes relating to the challenges of sourcing food and delivering meals were the cost of food and restricted budgets; reliance on surplus food; staffing and meal planning; and inad- equate facilities and equipment at hub settings.

Hub leaders highlighted the issue of the cost of food: "It is expensive and the funding provided by Kitchen Social doesn't cover the costs" (Hub leader 2). Thus, due to restricted financial budgets, hub leaders endeavored to source food from a range of sources. Although there are cost advantages to receiving and using surplus food donations, this strategy of food procurement created challenges for hub leaders. The type and quantity of donated food items varied on a weekly basis, which made it difficult for hub leaders to plan menus: "When receiving surplus food, it makes it harder to plan for your meals. We end up sometimes having to shop in supermarket stores" (Hub leader 45). Moreover, hub leaders shared the challenges of receiving inappropriate food items in their surplus food deliveries: "The Felix Project provided us with surplus food. This was excellent but occasionally the food wasn't appropriate for making lunches with children. Our budget with Kitchen Social meant we could override this issue" (Hub leader 38). Thus, hub leaders either donated unwanted surplus food items to local families or foodbanks.

Twelve holiday hub leaders described the challenge of recruiting experienced staff or volunteers with the necessary skills to plan and prepare meals at the holiday hubs. Food preparation duties were time consuming and often in addition to the leadership and / or youth provision work that staff are recruited to undertake. Hub leaders reported that planning meals, procuring food, and preparing lunches required careful planning and were labor intensive:

The playgrounds where lunches are prepared are very busy. Occasionally, children's issues on sites make it difficult for staff to prioritize food. However lunches were always provided. (Hub leader 38)

The lack of volunteers to assist the project. This often falls to staff to step outside of their role to support [with delivering meals]. (Hub leader 39)

Findings from observational data illustrated 
that a number of staff had limited catering experience, and as a result the hub leader of an adventure playground planned all meals and purchased food every morning prior to arriving at the hub and setting up the holiday hub session. Furthermore, for many holiday hubs, fluctuations in daily attendance rates added an additional challenge for purchasing food and planning meals: "Some days we had 15 kids plus 3 staff to make a hot meal for, basically healthy and they would like it" (Hub leader 33). Many of the hub leaders reported that they followed a menu plan and endeavored to follow School Food Standards. Nevertheless, while they used these standards as a reference tool, they did not weigh food or control portion sizes. It is evident from observational data at both the adventure playground and the youth club that meals served at the hub depended on food surplus donations, and food served on Fridays tended to be leftovers to reduce food waste and save costs.

Finally, holiday hub leaders reported the issue of inadequate facilities and equipment to store food and prepare meals, which made it difficult to bulk buy food and prepare meals:

Because of limited storage space we struggle with receiving and storing fresh food donations. (Hub leader 36)

Some of our equipment is on its last legs and transporting it all around the neighborhood was a bit tricky. (Hub leader 26)

Moreover, observations from the adventure playground recorded the challenges of inadequate cooking equipment and lack of storage facilities that prevented the hub from storing a pantry of food items or storing leftover food. Consequently, the holiday hub leader was required to purchase food on a daily basis and could not benefit from bulk buying food items from wholesalers.

\section{Discussion}

The aim of the current study was to investigate how holiday hub leaders procure food and deliver meals, and the opportunities and challenges experienced with sourcing food and delivering meals at holiday hubs to children and young people. The findings of this study showed that holiday hubs are operating in disadvantaged communities of London and delivering free meals, often more than one meal per day, to children and young people for approximately half the number of days in the school summer holidays. Holiday hub leaders endeavored to serve healthy meals to children, and owing to limited finances, they adopted a variety of methods to procure food via food purchases and donations from food stores, restaurants, catering organizations, community food projects, food redistribution organizations, and food aid charities. Community organizations are reliant on external funding to deliver a program of holiday provision (Mann et al., 2020). Prior research on food hubs in the U.S. that aim to improve food access in disadvantaged communities indicate that these food hubs are dependent on funding and suggest a need for long-term public support for these food system initiatives (Hoey et al., 2018). Nevertheless, while holiday hub leaders sought opportunities to source food cost-effectively, the findings suggest that the hubs face numerous challenges to deliver meals that comply with School Food Standards.

The views of hub leaders in the current study lend support to previous research that the delivery of holiday provision relies on the relationships and networks of holiday hub staff (Mann et al., 2020; Stretesky et al., 2020). Holiday hub leads brokered relationships with a range of organizations, including local food producers, food suppliers, restaurants, catering organizations, and food aid charities in their communities to procure sufficient food to ensure that all children attending their holiday hub received a meal. The findings showed a range of strategies employed by hub leaders to source food, e.g., negotiated reduced prices, received weekly donated food items and surplus food donations, and in some cases outsourced the preparation and delivery of meals by using local businesses and organizations such as restaurants, community organizations, and catering colleges. In addition to developing connections and networks across the community, hub leaders reported that staff have acquired new skills and undergone training, and children and young people have been involved in the planning and preparation of meals. Thus, holiday hubs can contribute to developing the capacity 
and resilience of a community by upskilling staff, volunteers, and attendees; building partnerships across sectors; and contributing to sustainable community development and resilience (Chaskin, 2009; Dale \& Newman, 2008). Community resilience is an ongoing process involving collective action and collaboration to improve the social and economic situation of a community (Cavaye \& Ross, 2019). In 2020, the Greater London Authority published its strategy on developing London as a resilient city and highlighted the need for interventions to increase resilience and support food security for vulnerable Londoners (Greater London Authority, 2020). Findings from this current study demonstrate that holiday hubs have the ability to align with this strategy of developing resilience in disadvantaged communities of London.

The findings from this study clearly demonstrate that community organizations can deliver a comprehensive program of food provision and activities to children and young people living in disadvantaged communities. Nevertheless, it is evident that there were challenges with procuring food and providing healthy meals: lack of statutory guidelines; small financial budgets; reliance on surplus food donations; lack of capacity and skills of staff; and inadequate facilities and equipment at holiday hub settings. Unlike school food procurement policies, where there are a framework and guidance for sourcing catering services (DfE, 2021), there is no comparable framework for community organizations to procure food and deliver meals in community settings. The mayor of London published the London Food Strategy in 2018, which recognizes that food served in local community centers and settings has the potential to reduce food insecurity and build inclusive communities (Greater London Authority, 2018). In addition, the London Food Strategy advocates that local community centers play a role in promoting a healthy and sustainable environment, and notes that this can be facilitated by participating in London's Healthier Catering Commitment (to promote healthy food items) and Sustain's Sugar Smart Campaign (a national initiative that aims to reduce the amount of sugar consumed) (Greater London Authority, 2018).
Nevertheless, the findings from the current study also show that community organizations are constrained by relatively small budgets and as a result rely on a variety of methods to secure food. These multiple procurement strategies can provide opportunities to support local businesses and organizations, reduce surplus food waste, and help to develop sustainable food environments. However, they equally created challenges for hub leaders with planning and preparing meals that comply to School Food Standards.

In recent years there has been a greater focus on the issue of food waste and, at the same time, a growth in food aid programs to support households at risk of food insecurity (Caraher \& Furey, 2017). Consequently, with the need to supply food to food aid programs, these programs have been viewed as part of a solution to the issue of food waste (Riches, 2002). While these food aid programs endeavor to deliver healthy food, the reliance on food donations means that meals may not comply with nutritional guidelines or meet specific dietary needs for those who rely on them (Caraher \& Furey, 2017; Tarasuk \& Eakin, 2005). Prior research on school and community-based nutrition programs in the U.S. indicate that while a goal of these feeding programs is to provide healthy meals to improve the nutrition of all recipients, budget constraints mean that program operators readily accept food donations from local businesses and cannot guarantee the nutritional adequacy of their meals (Raine et al., 2003). Moreover, the unpredictability of supply and limited choice mean that surplus food reduces the ability for hub leaders to provide standardized, nutritionally balanced meals and cannot be relied upon to meet need (Caraher $\&$ Furey, 2017). While there are notable benefits of using food surplus donations to not only reduce food waste but also food costs, it raises the question of whether the use of surplus food improves the access to healthy food for children living in disadvantaged communities and addresses social justice or people's right to food (Caraher \& Furey, 2017).

The provision of healthy food is an equally important factor in addressing obesity. It is evident that the poorest in society are more likely to suffer from hunger and obesity (Dimbleby, 2020; 
Goisis et al., 2015). Children living in the most deprived neighborhoods in the UK are three times more likely to be obese by aged 11 years compared to their peers living in the most affluent neighborhoods (Goisis et al., 2015). While the mayor of London advocates healthy eating initiatives in the London Food Strategy released in 2018, the findings from this study demonstrate that further support is required for holiday hubs in terms of funding and guidelines to secure procurement of healthy food items, and that food provision is aligned with wider national strategies addressing food security and obesity. The recent publication of part one of the National Food Strategy seeks to address the inequities in the food system and ensure that the food system delivers safe, healthy, and affordable food to all, regardless of location or earnings (Dimbleby, 2020). Healthy food procurement policies can improve the availability of healthier foods for children living in disadvantaged communities; however, community organizations need a secure funding stream to ensure healthy food procurement methods as well as adequate food storage and facilities and the staff with the skills to handle perishable foods and prepare meals (Caraher \& Dowler, 2007; Caraher \& Furey, 2017; K. D. Raine et al., 2018).

\section{Conclusion}

The current findings offer a timely contribution to the research literature in this area given the National Food Strategy (Part One) recommendation that access to the government-funded Holiday Food and Activities Program be extended to all children eligible for FSM in England (Dimbleby, 2020). This study provides an important account of hub leaders' views on the challenges of procuring food and delivering meals at holiday hubs to children and young people. While there are strengths in the mixed-methods design employed in this study, it is acknowledged that these holiday hubs operate in a program of holiday provision in London and the findings cannot be generalized across the UK. Furthermore, future research is needed to explore the impact of food provision and delivery of meals at holiday hubs in terms of health and diets of children and young people. Community organizations are well positioned to deliver holiday provision in underserved communities and have the ability to broker relationships, develop networks, and upskill community members to deliver meals during the school holidays. Importantly, the findings illustrate that continued, significant government investment is required to support holiday programs to deliver nutritious meals and activities to children.

\section{References}

Board of Science, British Medical Association. (2015). Food for thought: Promoting healthy diets among children and young people. British Medical Association. https://bma.primo.exlibrisgroup.com/permalink/44BMA INST/b10urm/alma990000943230206796

Burgoine, T., Sarkar, C., Webster, C. J., \& Monsivais, P. (2018). Examining the interaction of fast-food outlet exposure and income on diet and obesity: Evidence from 51,361 UK Biobank participants. International Journal of Behavioral Nutrition and Physical Activity, 15, Article 71. https://doi.org/10.1186/s12966-018-0699-8

Caraher, M., \& Dowler, E. (2007). Food projects in London: Lessons for policy and practice-A hidden sector and the need for "more unhealthy puddings ... sometimes." Health Education Journal, 66(2), 188-205. https://doi.org/10.1177/0017896907076762

Caraher, M., \& Furey, S. (2017). Is it appropriate to use surplus food to feed people in hunger? Short-term Band-Aid to more deep rooted problems of poverty. Food Research Collaboration.

Cavaye, J., \& Ross, H. (2019). Community resilience and community development: What mutual opportunities arise from interactions between the two concepts? Community Development, 50(2), 181-200. https://doi.org/10.1080/15575330.2019.1572634

Chaskin, R. J. (2009). Building community capacity for children, youth and families. Children Australia, 34(1), 31-38. https://doi.org/10.1017/S1035077200000511

Dale, A., \& Newman, L. (2008). Social capital: A necessary and sufficient condition for sustainable community development? Community Development Journal, 45(1), 5-21. https://doi.org/10.1093/cdj/bsn028 
Darmon, N., \& Drewnowski, A. (2015). Contribution of food prices and diet cost to socioeconomic disparities in diet quality and health: A systematic review and analysis. Nutrition Reviews, 73(10), 643-660. https://doi.org/10.1093/nutrit/nuv027

Defeyter, M. A., Graham, P. L., \& Prince, K. (2015). A qualitative evaluation of holiday breakfast clubs in the UK: Views of adult attendees, children, and staff. Frontiers in Public Health, 3(199). https://doi.org/10.3389/fpubh.2015.00199

Department for Education [DfE]. (2016). School food in England: Departmental advice for governing boards. Retrieved from the Digital Education Resource Archive: https://dera.ioe.ac.uk//26878/

DfE. (2019). Schools, pupils and their characteristics: January 2019. https://www.gov.uk/government/statistics/schools-pupils-and-their-characteristics-january-2019

DfE. (2021). Buying for schools. https://www.gov.uk/guidance/buying-for-schools/catering-services

Department for Health. (2005). Choosing a better diet: A food and health action plan. Rertrieved from the Digital Education Resource Archive: https://dera.ioe.ac.uk/7558/

Department for Work and Pensions [DWP]. (2021). Households below average income (HBAI) statistics. https://www.gov.uk/government/collections/households-below-average-income-hbai--2

Dimbleby, H. (2020). National Food Strategy: Part One. https://www.nationalfoodstrategy.org/

Dowler, E., \& Lambie-Mumford, H. (2015). How can households eat in austerity? Challenges for social policy in the UK. Social Policy and Society, 14(03), 417-428. https://doi.org/10.1017/S1474746415000032

Driessen, C. E., Cameron, A. J., Thornton, L. E., Lai, S. K., \& Barnett, L. M. (2014). Effect of changes to the school food environment on eating behaviours and/or body weight in children: A systemic review. Obesity Reviews, 15(12), 968-982. https://doi.org/10.1111/obr.12224

Food Standards Agency. (2019). The Food and You Survey, W ave 5. Food Standards Agency. https://www.food.gov.uk/research/food-and-you/food-and-you-wave-five

Gill, O., \& Sharma, N. (2004). Food poverty in the school holidays. Barnardo’s South West England.

Ginn, A., Majumdar, A., Carr, M., Eastwood, G., \& Menger, B. (2016). Mapping access to community-developed healthy food baskets including cost and availability. Health Education Journal, 75(8), 911-924. https://doi.org/10.1177/0017896916632789

Goisis, A., Sacker, A., \& Kelly, Y. (2015). Why are poorer children at higher risk of obesity and overweight? A UK cohort study. European Journal of Public Health, 26(1), 7-13. https://doi.org/10.1093/eurpub/ckv219

Graham, P. L., Crilley, E., Stretesky, P. B., Long, M. A., Palmer, K. J., \& Defeyter, M. A. (2016). School holiday food provision in the UK: A qualitative investigation of needs, benefits and potential for development. Frontiers in Public Health, 4, Article 172. https://doi.org/10.3389/fpubh.2016.00172

Greater London Authority. (2018). The London Food Strategy: Healthy and sustainable food for London. https://www.london.gov.uk/what-we-do/communities/food/london-food-strategy-0

Greater London Authority. (2020). London City resilience strategy 2020. https://www.london.gov.uk/what-we-do/fire-and-resilience/london-city-resilience-strategy

Hoey, L., Fink Shapiro, L., \& Bielaczyc, N. (2018). "Put on your own mask on before helping someone else": The capacity of food hubs to build equitable food access. Journal of Agriculture, Food Systems, and Community Development, 8(3), 41-60. https://doi.org/10.5304/jafscd.2018.083.012

Holley, C. E., Mason, C., \& Haycraft, E. (2019). Opportunities and challenges arising from holiday clubs tackling children's hunger in the UK: Pilot club leader perspectives. Nutrients, 11(6), Article 1237. https://doi.org/10.3390/nu11061237

House of Lords. (2020). Hungry for change: Fixing the failures in food (HL Paper 85). https://publications.parliament.uk/pa/ld5801/ldselect/ldfphe/85/8502.htm

Joint World Health Organization [WHO]/Food and Agriculture Organization of the United Nations [FAO] Expert Consultation on Diet, Nutrition and the Prevention of Chronic Diseases. (2003). Diet, nutrition and the prevention of chronic diseases: Report of a joint WHO/FAO expert consultation (WHO Technical Report Series No. 916). WHO. https://www.who.int/publications/i/item/924120916X 
Jones, N. R. V., Conklin, A. I., Suhrcke, M., \& Monsivais, P. (2014). The growing price gap between more and less healthy foods: Analysis of a novel longitudinal UK dataset. PLOS ONE, 9(10), Article 109343. https://doi.org/10.1371/journal.pone.0109343

Leeser, R. (2020). Poverty in London 2017/18. https://data.london.gov.uk/blog/poverty-in-london-2018-19/

Long, M. A., Gonçalves, L., Stretesky, P. B., \& Defeyter, M. A. (2020). Food insecurity in advanced capitalist nations: A review. Sustainability (Switzerland), 12(9), Article 3654. https://doi.org/10.3390/su12093654

Long, M. A., Stretesky, P. B., Graham, P. L., Palmer, K. J., Steinbock, E., \& Defeyter, M. A. (2018). The impact of holiday clubs on household food insecurity-A pilot study. Health and Social Care in the Community, 26(2), e261-e269. https://doi.org/10.1111/hsc.12507

Long, R. (2019). The school day and year (England) (Issue 07148). House of Commons Library. https://www.parliament.uk/commons-library

Loopstra, R., \& Tarasuk, V. (2015). Food bank usage is a poor indicator of food insecurity: Insights from Canada. Social Policy and Society, 14(3), 443-455. https://doi.org/10.1017/S1474746415000184

Mann, E., Long, M. A., Stretesky, P. B., \& Defeyter, M. A. (2018). A question of justice: Are holiday clubs serving the most deprived communities in England? Local Environment, 23(10), 1008-1022. https://doi.org/10.1080/13549839.2018.1518415

Mann, E., Widdison, C., \& Defeyter, M. A. (2020). Implementing holiday provision programmes: A qualitative investigation of the experiences of senior stakeholders. Open Journal of Social Sciences, 8(7), 286-302. https://doi.org/10.4236/jss.2020.87023

Marmot, M., Allen, J., Boyce, T., Goldblatt, P., \& Morrison, J. (2020). Health equity in England: The Marmot Review 10 years on. Institute of Health Equity. https://www.instituteofhealthequity.org/resources-reports/marmot-review-10-years-on

Marmot, M., Allen, J., Goldblatt, P., Boyce, T., McNeish, D., Grady, M., \& Geddes, I. (2010). Fair society, healthy lives: Strategic review of health inequalities in England post-2010: The Marmot Review. Institute of Health Equity. https://www.instituteofhealthequity.org/resources-reports/fair-society-healthy-lives-the-marmot-review

Mayor's Fund for London. (2019). Kitchen Social. https://www.mayorsfundforlondon.org.uk/kitchen-social/

Ministry of Housing, Communities \& Local Government. (2019). English indices of deprivation 2019. https://www.gov.uk/government/statistics/english-indices-of-deprivation-2019

Morgan, K., McConnon, L., Van Godwin, J., Hawkins, J., Bond, A., \& Fletcher, A. (2019). Use of the school setting during the summer holidays: Mixed-methods evaluation of food and fun clubs in Wales. Journal of School Health, 89(10), 829-838. https://doi.org/10.1111/josh.12824

Niebylski, M. L., Lu, T., Campbell, N. R. C., Arcand, J., Schermel, A., Hua, D., Yeates, K. E., Tobe, S. W., Twohig, P. A., L’Abbé, M. R., \& Liu, P. P. (2014). Healthy food procurement policies and their impact. International Journal of Environmental Research and Public Health, 11(3), 2608-2627. https:/ / doi.org/10.3390/ijerph110302608

Public Health England. (2016). From plate to guide: What, why and how for the eatwell model. https://assets.publishing.service.gov.uk/government/uploads/system/uploads/attachment data/file/579388/eatw ell model guide report.pdf

Public Health England. (2018). England's poorest areas are fast food hotspots. https://www.gov.uk/government/news/englands-poorest-areas-are-fast-food-hotspots

Raine, K. D., Atkey, K., Olstad, D. L., Ferdinands, A. R., Beaulieu, D., Buhler, S., Campbell, N., Cook, B., L’Abbé, M., Lederer, A., Mowat, D., Maharaj, J., Nykiforuk, C., Shelley, J., \& Street, J. (2018). Healthy food procurement and nutrition standards in public facilities: Evidence synthesis and consensus policy recommendations. Health Promotion and Chronic Disease Prevention in Canada, 38(1), 6-17. https://doi.org/10.24095/hpcdp.38.1.03

Raine, K., McIntyre, L., \& Dayle, J. B. (2003). The failure of charitable school- and community-based nutrition programmes to feed hungry children. Critical Public Health, 13(2), 155-169. https://doi.org/10.1080/09581590302768

Riches, G. (2002). Food banks and food security: Welfare Reform, human rights and social policy. Lessons from Canada? Social Policy and Administration, 36(6), 648-663. 
Ridge, T. (2002). Childhood poverty and social exclusion: The child's perspective. The Policy Press. https://doi.org/10.2307/j.ctt1t8986p

Scientific Advisory Committee on Nutrition [SACN]. (2012). SACN dietary reference values for energy. Public Health England. https://www.gov.uk/government/publications/sacn-dietary-reference-values-for-energy

Scott, C., Sutherland, J., \& Taylor, A. (2018). Affordability of the UK's Eatwell Guide. The Food Foundation. https://foodfoundation.org.uk/sites/default/files/2021-10/Affordability-of-the-Eatwell-Guide Final WebVersion.pdf

Stretesky, P. B., Defeyter, M. A., Long, M. A., Sattar, Z., \& Crilley, E. (2020). Holiday clubs as community organizations. The Annals of the American Academy of Political and Social Science, 689(1), 129-148. https://doi.org/10.1177/0002716220917657

Swensson, L. F. J., \& Tartanac, F. (2020). Public food procurement for sustainable diets and food systems: The role of the regulatory framework. Global Food Security, 25, Article 100366. https://doi.org/10.1016/i.gfs.2020.100366

Tarasuk, V., \& Eakin, J. M. (2005). Food assistance through “surplus” food: Insights from an ethnographic study of food bank work. Agriculture and Human Values, 22, 177-186. https://doi.org/10.1007/s10460-004-8277-x

Thornton, L. E., Pearce, J. R., \& Ball, K. (2014). Sociodemographic factors associated with healthy eating and food security in socio-economically disadvantaged groups in the UK and Victoria, Australia. Public Health Nutrition, 17(1), 20-30. https://doi.org/10.1017/S1368980013000347

Trussell Trust. (2019, July 16). UK food banks fear busiest summer ever is ahead. https://www.trusselltrust.org/2019/07/16/uk-food-banks-fear-busiest-summer-ever-ahead/

Van Cauwenberghe, E., Maes, L., Spittaels, H., van Lenthe, F. J., Brug, J., Oppert, J.-M., \& De Bourdeaudhuij, I. (2010). Effectiveness of school-based interventions in Europe to promote healthy nutrition in children and adolescents: Systematic review of published and 'grey' literature. British Journal of Nutrition, 103(6), 781-797. https://doi.org/10.1017/S0007114509993370

Wang, D., \& Stewart, D. (2013). The implementation and effectiveness of school-based nutrition promotion programmes using a health-promoting schools approach: A systematic review. Public Health Nutrition, 16(6), 10821100. https://doi.org/10.1017/S1368980012003497

Williamson, S., McGregor-Shenton, M., Brumble, B., Wright, B., \& Pettinger, C. (2017). Deprivation and healthy food access, cost and availability: A cross-sectional study. Journal of Human Nutrition and Dietetics, 30(6), 791-799. https://doi.org/10.1111/jhn.12489 